\title{
IMMUNISATION RATES FOR KINDERGARTEN CHILDREN OF THE SOUTH WEST REGION
}

Kim Gilchrist and Tony Kolbe, South West Region Public Health Unit

mmunisation remains one of the most effective public health activities. Despite this, and the availability of public and private immunisation services, immunisation coverage rates are not sufficient to prevent the transmission of vaccine-preventable diseases. The 1989-1990 National Health Survey (NHS) conducted by the Australian Bureau of Statistics (ABS) found that 53 per cent of children less than six years old had received full age-appropriate immunisation'.

Data on immunisation coverage for the South West Region (SWR) were lacking. This cross-sectional survey was initiated to provide baseline immunisation coverage data on children in kindergarten in 1992. Although the survey gives little information on age-appropriate immunisation, it does provide a snapshot of immunisation coverage and will provide valuable data against which the impact of initiatives in immunisation will be assessed.

The survey was conducted with the assistance of school health nurses (SHNs) who distributed questionnaires to all eligible kindergarten children in schools in their district. The forms were taken home by the children and returned to the SHN who recorded the numbers of questionnaires sent out and received back.

The questionnaire was in the form of an explanatory letter with tear-off questionnaire. Parents were asked to tick yes, no or unsure to whether their child had been immunised with the stated vaccine. Language spoken at home and Aboriginality of the child were asked as well as the source of the information (i.e. Personal Health Record (PHR), parent's memory, or elsewhere). The questionnaires were returned to the PHU for data entry and analysis.

Of the 4,243 questionnaries given out, 3,666 were returned. The response was 86.4 per cent (95\% CI: $85.4-87.4 \%$ ).

For children returning the questionnaire, 84 per cent were fully immunised, 16 per cent had incomplete immunisation (i.e. one or more of the immunisations missing) and 0.4 per cent had no immunisations.

The rate of complete immunisation varied by Local Government Area (LGA), ranging from 45 per cent in Corowa to 100 per cent in Urana and Jerilderie, with 20 of the 28 LGAs having greater than 85 per cent complete immunisations. The major contributing factor to this difference is the variation in the rate of immunisation for the pre-school/five-year booster.

Ninety-eight per cent of respondents came from English speaking households. This is consistent with regional information stating that about 93 per cent of residents of the South West Region were born in Australia. The rate of complete immunisation was significantly higher for children of English speaking households 84 per cent (95\% CI: 83$86 \%$ ) than for respondents from a non-English speaking background at 62 per cent ( $95 \%$ CI: $50-74 \%$ ).

Aboriginality was unavailable for 285 of the 3,666 respondents. There was variation both in the number of Aboriginal children and coverage rate by LGA. Complete immunisation status was slightly lower for Aborigines ( 80 per cent) than non-Aborigines ( 84 per cent) (Table 9 ).

\section{TABLE 9}

IMMUNISATION STATUS BY LANGUAGE SPOKEN AT HOME, ABORIGINALITY AND FOR ALL RESPONDENTS

\begin{tabular}{|c|c|c|c|c|c|}
\hline \multirow[t]{2}{*}{ Immunisation status } & \multicolumn{2}{|c|}{ Language spoken at home } & \multicolumn{2}{|c|}{ Aboriginality } & \multirow{2}{*}{$\begin{array}{c}\text { All respondents } \\
\mathrm{n}(\%)\end{array}$} \\
\hline & $\begin{array}{l}\text { English } \\
\text { n (\%) }\end{array}$ & $\begin{array}{c}\text { NESB\#\# } \\
\text { n (\%) }\end{array}$ & $\begin{array}{c}\text { Non- } \\
\text { Aboriginal } \\
\mathrm{n}(\%)\end{array}$ & $\begin{array}{c}\text { Aboriginal } \\
\text { n (\%) }\end{array}$ & \\
\hline Complete & * *3,029(84.3) & **38 (62.3) & $2,759(84.1)$ & $82(80.4)$ & $3,076(83.9)$ \\
\hline Incomplete & $550(15.3)$ & $22(36.1)$ & $508(15.5)$ & $19(18.6)$ & $576(15.7)$ \\
\hline None & $13(0.4)$ & $1(1.6)$ & $12(0.4)$ & $1(1.0)$ & $14(0.4)$ \\
\hline Total & $3,592(100)$ & $61(100)$ & $102(100)$ & $3,279(100)$ & $3,666(100)$ \\
\hline
\end{tabular}

** indicates a significant difference at alpha $=0.05$

\#\# NESB (Non-English speaking background) component is made up of 23 children from Italian speaking households and the remaining 38 are from 19 other language groups with a frequency of no greater than 4 .

\section{TABLE 10}

COMPLETE IMMUNISATIONS BY VACCINE TYPE

\begin{tabular}{|c|c|c|c|c|c|}
\hline \multirow[t]{2}{*}{ Vaccine type } & \multicolumn{2}{|c|}{ Language spoken at home } & \multicolumn{2}{|c|}{ Aboriginality } & \multirow{2}{*}{$\begin{array}{c}\text { All respondents } \\
n(\%)\end{array}$} \\
\hline & $\begin{array}{l}\text { English } \\
\text { n (\%) }\end{array}$ & $\begin{array}{l}\text { NESB } \\
\text { n (\%) }\end{array}$ & $\begin{array}{c}\text { Non- } \\
\text { Aboriginal } \\
\mathrm{n}(\%)\end{array}$ & $\begin{array}{c}\text { Aboriginal } \\
n(\%)\end{array}$ & \\
\hline $3 \times$ Triple antigen/Sabin & $3,534(98.4)$ & $55(90.2)$ & $3,228(98.4)$ & $99(97.1)$ & $3,327(98.2)$ \\
\hline Measles/mumps & $3,469(96.9)$ & $55(91.7)$ & $3,170(97.0)$ & 95 (93.1) & $3,265(96.7)$ \\
\hline TA booster/Sabin & $3,446(96.2)$ & $52(86.7)$ & $3,144(96.2)$ & $96(94.1)$ & $3,240(96.0)$ \\
\hline Preschool entry booster & $3,142(88.5)$ & $41(69.5)$ & $2,861(88.4)$ & $87(86.1)$ & $2,948(88.2)$ \\
\hline
\end{tabular}




\section{Immunisation rates}

\section{Continued from page 71}

Excellent coverage rates were achieved for vaccines other than the pre-school booster with most LGAs showing rates above 95 per cent for triple antigen/Sabin, measles/mumps and the 18-month booster. Three LGAs showed coverage rates of less than 95 per cent for measles/mumps immunisation.

Generally, Aboriginal children had lower coverage rates for all vaccines when compared with non-Aboriginal children, although coverage rates were still good.

The majority of parents consulted their child's PHR to complete the survey and in some cases more than one source was indicated. Other sources of information included the child's general practitioner and the SHN (Table 11).

\section{TABLE 11}

SOURCE OF CHILD'S IMMUNISATION INFORMATION

\begin{tabular}{|lrr|}
\hline Source & Number & $\begin{array}{r}\text { Percentage of } \\
\text { responses }\end{array}$ \\
\hline Parent's memory & 1,288 & 35.1 \\
Personal Health Record & 2,253 & 61.5 \\
Other source & 131 & 3.6 \\
\hline
\end{tabular}

\section{DISCUSSION}

Since high immunisation coverage rates are required to prevent transmission of some vaccine-preventable diseases, particularly measles, it is important to attempt to achieve a high response rate in a coverage survey such as this. Our results may be an overestimate of the true immunisation coverage rate if those parents not returning questionnaires were less likely to have had their children immunised.

Generally, the coverage rates for the SWR are better than those reported in the NHS, although direct comparisons are difficult. For 5-6-year-olds in the NHS the immunisation rate ranged from 66 per cent for pertussis to 99 per cent for measles, while 24 per cent had partial polio immunisation and 8.3 per cent had partial immunisation against diphtheria/tetanus. Less than 1 per cent reported no immunisation against diphtheria/tetanus and 7 per cent reported no measles immunisation ${ }^{1}$.

The NHS data and the SWR survey data indicate that the lack of the pre-school/five-year booster is a major factor contributing to incomplete immunisation coverage in children aged 5-6. If the pre-school/five-year booster data are not included the coverage rate for the SWR increases to 94 per cent. The National Health and Medical Research Council (NHMRC) recommendation for a pre-school booster ${ }^{2}$ should be promoted as pre-school or five years of age, whichever comes first. It is unknown whether the low rate for the pre-school/five-year booster reflects a "missed" immunisation or that the parents are waiting for the child's fifth birthday.

Significantly lower rates of full immunisation coverage were found for children where a language other than English was the main language at home (Table 1). The NHS data showed that children of parents born overseas were less likely to be fully immunised ${ }^{1}$. This emphasises the need for special efforts to achieve full immunisation coverage in children of NESB. Personal follow-up of NESB families may be appropriate as there are small numbers from a wide range of language backgrounds. Interestingly, almost all NESB children without full immunisation had at least commenced the schedule. This indicates some contact with an immunisation provider and must be classed as a breakdown in any follow-up system.

Good immunisation coverage was found for Aboriginal children. The number of questionnaires returned without the section on Aboriginality completed and the potential number of Aboriginal children in the 14 per cent of nonrespondents is of concern. This survey may overestimate the immunisation coverage in Aboriginal children because of these factors.

More parents consulted their child's PHR for immunisation information than was reported in the NHS where, in 45 per cent of cases, immunisation records were consulted ${ }^{1}$. There is concern that data based on parental recall may produce an overestimate of immunisation coverage. The PHR, now to be called The Blue Book, must be promoted to parents and immunisation providers as the preferred form of documentation. Parents should be encouraged to take the PHR whenever the child is having contact with the health system and health professionals should be encouraged to check the PHR, to immunise at all appropriate opportunities and to record the details in the child's PHR.

Although the survey indicates good immunisation coverage for children attending kindergarten it gives little indication as to whether these children had been immunised at the ages recommended by the NHMRC. A better assessment of age-appropriate immunisation and immunisation services would be obtained by surveying children about two years of age.

Improvement in age-appropriate immunisation may be achieved through provider-based immunisation registers which could issue reminder notices and facilitate the followup of children not being immunised. Innovative and special efforts may be required to immunise children who do not receive immunisation through "normal" public or private immunisation services.

Apart from coverage, other aspects of immunisation services must be addressed. Assessment of the cold chain system, standards of practice for public immunisation services and cooperation with general practitioners are of major importance. The health system must be made aware of missed opportunities for immunisation, there must be improved surveillance of vaccine-preventable disease and adverse events following immunisation and ultimately serological studies need to be conducted to assess vaccine efficacy. The knowledge of parents and immunisation providers must be improved and maintained and the arguments against immunisation effectively and convincingly dismissed.

1. Australian Bureau of Statistics. 1989-1990 National Health Survey. Children's immunisation, Australia Catalogue No. 4379.0, 1992. 2. National Health and Medical Research Council. Immunisation Providers 4th Edition, Canberra: Australian Government Publishing Service, 1991.

\section{ACKNOWLEDGMENTS}

We thank the school health nurses in the South West Region for their assistance and enthusiasm and the community health coordinators for their support. Ms Kelly Stork entered and collated the data and her contribution was greatly appreciated. 